\title{
DIAGNOSTIC EVALUATION OF BLOODY PLEURAL EFFUSION
}

Mamatha S, Manish Kumar Singh, Pravati Dutta, Rekha Manjhi, Sudarsan Pothal,Amit Kumar Jha, Nilam Nigam, Sanjay Kumar Nigam

1. Senior Resident, Department of Respiratory Medicine,SGPGIMS, Lucknow,

2. Assistant Professor, Department of Medicine, Rama Medical College Hospital \& Research Centre, Mandhana Kanpur, U.P.

3. Professor, Department of Pulmonary Medicine, V.S.S.M.C.H, Burla, Sambhalpur, Odisha.

4. Associate Professor, Department of Pulmonary Medicine, V.S.S.M.C.H, Burla, Sambhalpur, Odisha.

5. Assistant Professor, Department of Pulmonary Medicine, V.S.S.M.C.H, Burla, Sambhalpur, Odisha.

6. Assistant Professor, Department of Community Medicine, Rama Medical College Hospital \& Research Centre, Mandhana Kanpur, U.P.

7. Professor, Department of Pharmacology, Rama Medical College Hospital \& Research Centre, Mandhana Kanpur, U.P.

8. Professor, Department of Pathology, Rama Medical College Hospital \& Research Centre, Mandhana Kanpur, U.P.

\section{CORRESPONDING AUTHOR}

\section{Dr. M. K. Singh}

House No. 206,

Rama Medical College, Mandhana

Kanpur, U.P

E-mail: dr.manishkumarsingh@yahoo.com

Ph: 00917376070025.

ABSTRACT: INTRODUCTION: Pleural involvement is common in various respiratory diseases including inflammatory, infectious, occupational or neoplastic entities. Pleural effusions are a common medical problem and are occasionally intractable. In order to determine the etiology of pleural effusions, it has been widely recommended to assess the appearance of pleural fluid at thoracentesis. Bloody pleural effusions are associated particularly with malignant aetiologies. Pleural fluid analysis is the key component in the diagnosis and management of pleural effusion. Etiology of bloody pleural effusion not only encompasses malignancy but also a diverse set of other clinical entities.

\section{AIMS AND OBJECTIVES:}

- Categorize bloody pleural fluid into blood-tinged, haemorrhagic effusions and hemothorax based on pleural fluid haematocrit

- To record their frequency in relation to diagnosis and to evaluate its cause.

MATERIAL AND METHODS:The patients who attended the Department of Pulmonary Medicine, V.S.S.M.C.H, Burla during the period of October 2009 to September 2011 were included in this study. RESULTS: In our study all 70 patients with bloody pleural effusion was taken and pleural fluid analysis revealed that the maximum number of patients i.e., 65 (92.85 \%) had their pleural fluid protein levels in the exudative range (i.e, $\geq 3.5 \mathrm{gm} \%$ ), remaining $5(7.14 \%$ ) had in the transudative range (i.e., $\leq 3 \mathrm{gm} \%$ ). The examination of pleural fluid cytology showed predominantly lymphocytes in 37 (52.85\%), RBCs \&degenerated polymorhonuclear cells in 19 (27.14\%), macrophages \& mesothelial cells in 6(8.57\%), eosinophils in $2(2.85 \%)$ \& neutrophils in $1(1.42 \%)$.Malignant cells were found in the pleural fluid in $11(15.71 \%)$. Malignancy was proved by CT guided FNAC in $10(14.28 \%)$ subjects. Bloody pleural effusion due to infection was 
predominantly caused due to tuberculosis in $7(53.84 \%)$, followed by parasitic aetiology in $3(23.07 \%)$, bacterial in $2(15.38 \%)$ and unidentified in $1(7.61 \%)$. Parasitic aetiology was identified to be due to Entamoeba histolytica in all 3 cases. CONCLUSION: Majority of bloody pleural effusions of infective etiology were caused by tuberculosis, followed by parasitic and bacterial infections. By malignancy, primary site of which was found to be in lung, followed by undiagnosed primary, breast, ovary, oral and Non-Hodgkin's lymphoma in the order of frequency. The second common presentation was blood-tinged effusion caused by traumatic tap or due to thickened pleura.

KEYWORDS: Pleural effusions; Hemothorax, Thoracentesis, Haemorrhagic pleural effusion

INTRODUCTION: Pleural effusion is accumulation of excessive pleural fluid in pleural space. Several mechanisms underlying pleural effusion include increased permeability of the pleural membrane, increased pulmonary capillary pressure, decreased negative intrapleural pressure, decreased oncotic pressure, and obstructed lymphatic flow. Bloody pleural effusions are a common occurrence during thoracentesis. Bloody pleural effusion can be caused by malignancy, trauma to chest, tuberculosis, non-tuberculous parapneumonic effusion, systemic lupus erythematosus, pulmonary embolism, fungal infection, anti-coagulant therapy, haemophilia, acute aortic dissection/thoracic aorta aneurysm ${ }^{[1]}$, pleural endometriosis, dialysis, sarcoidosis ${ }^{[2]}$, pleuritis associated with amoebic liver abscess ${ }^{3}$, haemorrhagic pancreatitis[4], pulmonary infarction ${ }^{[5]}$, microfilaria, post-operative cases of cardiac surgery[6,7] etc. Categorization of bloody pleural effusion is done based on pleural fluid haematocrit in comparison with peripheral blood haematocrit. Pleural fluid hematocrit $<1 \%$ of blood hematocrit was classified as blood-tinged effusion, the corresponding pleural fluid RBC counts would be between 5,000 and 100,000 per cumm ${ }^{[8]}$. More than $15 \%$ of transudative and more than $40 \%$ of all types of exudative pleural fluids are blood tinged [9]. Pleural fluid hematocrit in the range of $1-50 \%$ was categorized as haemorrhagic pleural effusion in which the pleural fluid RBC count would exceed 100000 per cumm. Hemothorax was the one with pleural fluid hematocrit $>50 \%$ of blood hematocrit.

\section{AIMS AND OBJECTIVES:}

- Categorize bloody pleural fluid into blood-tinged, haemorrhagic effusions and hemothorax based on pleural fluid haematocrit

- To record their frequency in relation to diagnosis and to evaluate its cause.

\section{MATERIAL AND METHODS:}

The patients who attended the Department of Pulmonary Medicine, V.S.S.M.C.H, Burla during the period of October 2009 to September 2011 were included in this study.

\section{INCLUSION CRITERIA:-}

- Patients who had bloody pleural effusion on thoracentesis.

- Subjects $>15$ years of age with bloody pleural effusion

\section{EXCLUSION CRITERIA:-}


- Patients who did not give consent to be included in the study.

- Patients in whom thoracentesis was contra-indicated - Patients receiving anti-coagulant therapy or having bleeding diathesis, uncooperative patient, only one functioning lung in patient.

METHODOLOGY: Informed consent of all the patients was taken. A detailed history and physical examination was done. Special note of history of trauma, malignancy (including history of treatment of malignancy in any form- surgery, radiotherapy, and chemotherapy) was done. The appearance of the fluid was assessed in a glass tube containing $10 \mathrm{~mL}$ of pleural fluid.

\section{IMAGING STUDIES:}

Chest radiographs- P-A view and lateral view, Ultrasonography examination of chest, thorax and pelvis, CT scan of thorax and abdomen.

Haemogram - Hb \%, DLC, TLC, BT, CT, peripheral blood haematocrit

FBS, S.urea, S.Creatinine, HIV antibody test, CEA, CA-125.

Sputum - AFB by Z-N staining, cytology for malignant cells.

FNAC of lymph node and chest wall swelling.

CT guided FNAC of parenchymal/pleural based lesion

THORACENTESIS: Patients with bloody pleural effusion on thoracentesis were included in the study. The appearance of pleural fluid was assessed in a clean glass tube. The fluid was analysed for biochemical (glucose, protein, and adenosine deaminase), cytology for differential count, malignant cells, microfilaria, trophozoites of E.H, Gram's stain, culture and sensitivity, etc.Pleural fluid hematocrit was determined.

After cumulative details of history, clinical examination and relevant investigations which could be possible in our setup, a final diagnosis was made in the categories of traumatic, infective, malignant, probably malignant, others and inconclusive.

TRAUMATIC bloody pleural effusion included those caused by iatrogenic and non-iatrogenic trauma.

INFECTIVE effusions were diagnosed by detection of organisms in pleural fluid or sputum by direct microscopy, Gram's stain or culture or response to therapy with anti-tubercular agents or antibiotics.

MALIGNANT EFFUSION- If pleural fluid cytology or pleural biopsy findings were positive for malignancy.

PROBABLY MALIGNANT- If the patient had known metastatic malignancy with no other explanation for the effusion and/or with repeated rapid accumulation of bloody pleural effusion.

INCONCLUSIVE for which a cause was not determined despite all the investigations that could be done in our set-up.

RESULTS: In this study, effusion 70 patients with bloody pleural on thoracentesis were included in the study. The appearance of pleural fluid was assessed in a clean glass tube. The fluid was analysed for biochemical (glucose, protein, and adenosine deaminase), cytology for differential count, malignant cells, microfilaria, trophozoites of E.H, Gram's stain, culture and sensitivity, etc. 
Pleural fluid hematocrit was determined. After cumulative details of history, clinical examination and relevant investigations which could be possible in our setup, a final diagnosis was made in the categories of traumatic, infective, malignant, probably malignant, others and inconclusive. The results hereby are discussed under separate headings for each variable.

DISCUSSION: In our study, maximum number of subjects were in the age group of 31-40 years21 subjects(30\%) with male predominance followed by equal number of males and females i.e.,7(10\%) each in 51-60 years range, $11(15.71 \%)$ in $41-50$ years, $9(12.85 \%)$ subjects each in 21-30 and $61-70$ years, $4(5.71 \%)$ subjects in $<20$ years group and $2(2.85 \%)$ subjects in $71-80$ years range. The number of males in my study were $45(64.28 \%)$ \& females being $25(35.71 \%)$ in number. The male: female ratio being 1: 1.8.The effusion was predominantly lymphocytic in $17(65.38 \%)$. Pleural lymphocytosis is common in malignancy and tuberculosis as described in a study done by N.A.Maskell et al. Y.C.Gary et al(2001) reported adenosine deaminase levels in nontuberculous lymphocytic pleural effusions seldom exceed the cut-off set for tuberculous effusions. An adenosine deaminase level < 40 IU x L (-1) virtually excluded a diagnosis of tuberculosis in lymphocytic pleural effusions. Their showed no correlation between the lymphocyte or monocyte counts and ADA activity in accordance with this study. The same study also revealed that there was no strong correlation between the ADA levels and the various haematological and biochemical parameters. It also concluded low ADA levels in lymphocytic pleural effusions virtually exclude the diagnosis of tuberculosis. In my study, bloody pleural effusion due to infection was predominantly caused due to tuberculosis in $7(53.84 \%)$, followed by parasitic etiology in 3(23.07\%), bacterial in 2(15.38\%) and unidentified in $1(7.61 \%)$. Parasitic etiology was identified to be due to Entamoeba histolytica in all 3 cases. All 3 cases had been diagnosed to have amoebic liver abscess at presentation, followed by development of pleural effusion. According to Ibarra Perez. $\mathrm{C}$ et al and Cameron EWJ et al, amoebic liver abscess produce pleural effusion when they rupture into pleural space. 1 case of bloody pleural effusion was due to non-dissecting thoracic aortic aneurysm on the left side. Similar case was reported by Sengupta et al(2007) and Shelley Shammim et al(2010).Compared with nonmalignant pleural effusions, patients with large or massive malignant pleural effusions were more likely to have pleural fluids with higher RBC counts $(18.0 \times 109$ cells/L vs $2.7 \times 109$ cells/L, respectively; $\mathrm{p}<0.001$ ) and lower adenosine deaminase (ADA) activity (11.5 vs $31.5 \mathrm{U} / \mathrm{L}$, respectively; $\mathrm{p}<$ 0.001), which were the two parameters that were selected by a stepwise logistic-regression model as independent predictors of malignancy according to the study done by Porcel JM et al(2003).

CONCLUSION: In our study, 70 patients who attended the Department of Pulmonary Medicine from October 2009 to September 2011 were included. This study was approved by the Institutional Ethical Committee. Informed consent of all the patients was taken after explaining about the details of the study. The male: female ratio in my study was 1.8:1. Males predominated in the age group of 31-40 years and females between 51-60 years. The most presenting symptom was breathlessness, followed by chest pain; cough with or without expectoration, fever and hemoptysis in the order of frequency. Moderate and massive pleural effusions predominated on the right side. Minimal effusions occurred in equal frequency on both sides. Bilateral effusions were moderately sized. Bloody pleural effusion was caused by malignancy in most of the subjects, followed by traumatic, inconclusive, infective, probably malignant and other aetiologies. Majority of bloody pleural effusions of infective etiology were caused by tuberculosis, followed by parasitic and bacterial infections. The most common 
presentation was haemorrhagic pleural effusion, majority caused by malignancy, primary site of which was found to be in lung, followed by undiagnosed primary, breast, ovary, oral and NonHodgkin's lymphoma in the order of frequency. The second common presentation was bloodtinged effusion caused by traumatic tap or due to thickened pleura. Hemothorax being least common in this study was caused by chest trauma and probably malignant effusion.

Pleural fluid analysis is the key component in the diagnosis and management of pleural effusion. This study was done to emphasize the importance of preliminary pleural fluid analysis in resource-limited settings where it still remains a very convenient, low cost and safe investigation that helps in arriving at a diagnosis swiftly while reducing the need for other invasive investigations. Etiology of bloody pleural effusion not only encompasses malignancy but also a diverse set of other clinical entities.

\section{BIBLIOGRAPHY:}

1. Sengupta P, Mitra B, Saha K, Maitra S, Pal J, Sarkar N. J Assoc Physicians India. 2007 Apr;55:297-300

2. Fraser, Muller, Colman, Pare - Diseases of chest.Vol 4-4th edition pg - 2739, 2765

3. Lyche KD, Jensen WA. Pleuropulmonaryamebiasis.SeminRespir Infect 1997;12:106-112

4. Kaye.M.D. Pleuropulmonary complications of pancreatitis.Thorax 23:297,1968

5. Griner.P.F.Bloody pleural fluid following pulmonary infarction

6. Mancini.M.Hemothorax:www.emedicine.com/med/topic2915.htm

7. National Library of medicine. Hemothorax,www.nlm.nih.gov/medlineplus/ency/article/000126.htm.

8. LightRW.Pleural diseases. $5^{\text {th }}$ edition.Pg.78.

9. LightRW, ErozanYS,Ball WC. Cells in pleural fluid: their value in differential diagnosis. Arch Intern Med1973; 64:591-596.

TABLE I-SYMPTOMATOLOGY OF PATIENTS WITH BLOODY PLEURAL EFFUSION

\begin{tabular}{|c|c|c|}
\hline Symptoms & No. of cases & Percentage \\
\hline Cough & 45 & 64.28 \\
\hline Chest pain & 55 & 78.57 \\
\hline Breathlessness & 58 & 82.85 \\
\hline Hemoptysis & 2 & 2.85 \\
\hline Fever & 27 & 38.57 \\
\hline
\end{tabular}

TABLE II-RADIOLOGICAL CLASSIFICATION OF BLOODY PLEURAL EFFUSION

\begin{tabular}{|l|l|l|l|l|l|l|l|}
\hline & Right & Percent & Left & Percent & Bilateral & Percent & Total \\
\hline Minimal & 1 & 1.42 & 1 & 1.42 & 0 & 0 & 2 \\
\hline Moderate & 25 & 35.71 & 9 & 12.85 & 4 & 5.71 & 38 \\
\hline Massive & 17 & 24.28 & 12 & 17.14 & 0 & 0 & 29 \\
\hline Encysted & 0 & 0 & 1 & 0 & 0 & 0 & 1 \\
\hline Total & 43 & & 22 & & 4 & & 70 \\
\hline
\end{tabular}


TABLE-III

\begin{tabular}{|c|c|c|c|c|c|}
\hline \multicolumn{5}{|c|}{ BIO-CHEMICAL ANALYSIS OF PLEURAL FLUID } \\
\hline $\begin{array}{c}\text { Pleural fluid } \\
\text { protein } \\
\text { (g/dL) }\end{array}$ & $\begin{array}{c}\text { No. of } \\
\text { cases }\end{array}$ & Percentage & $\begin{array}{c}\text { Pleural fluid } \\
\text { glucose(mg/dL) }\end{array}$ & $\begin{array}{c}\text { No. of } \\
\text { cases }\end{array}$ & Percentage \\
\hline$<3.5$ & 5 & 7.14 & $\leq 60$ & 34 & 48.57 \\
\hline$\geq 3.5$ & 65 & 92.85 & $>60$ & 36 & 51.42 \\
\hline Total & 70 & 100 & Total & 70 & $\mathbf{1 0 0}$ \\
\hline
\end{tabular}

\section{TABLE IV}

\begin{tabular}{|c|c|c|}
\hline \multicolumn{3}{|c|}{ PLEURAL FLUID ADENOSINE DE-AMINASE VALUES } \\
\hline ADA(IU/L) & No. of cases & Percentage \\
\hline $10-20$ & 11 & 15.71 \\
\hline $21-40$ & 21 & 30 \\
\hline $41-60$ & 18 & 25.71 \\
\hline $61-80$ & 9 & 12.85 \\
\hline $81-100$ & 1 & 1.42 \\
\hline
\end{tabular}

TABLE V -FREQUENCY OF OCCURENCE OF DIFFERENT TYPES OF BLOODY PLEURAL EFFUSION IN THIS STUDY

\begin{tabular}{|l|l|l|l|}
\hline Etiology & Blood-tinged & Haemorrhagic & Hemothorax \\
\hline Malignancy & 2 & 24 & 0 \\
\hline Probably malignant & 0 & 1 & 1 \\
\hline Traumatic & 11 & 1 & 2 \\
\hline Infective & 3 & 9 & 0 \\
\hline Others & 1 & 1 & 0 \\
\hline Inconclusive & 2 & 12 & 0 \\
\hline Total & $\mathbf{1 9 ( 2 7 . 1 4 \% )}$ & $\mathbf{4 8 ( 6 8 . 5 7 \% )}$ & $\mathbf{3 ( 4 . 2 8 \% )}$ \\
\hline
\end{tabular}

\section{TABLE VI -CYTOLOGICAL ANALYSIS OF PLEURAL FLUID}

\begin{tabular}{|c|c|c|}
\hline Pleural fluid cytology & No. of cases & Percentage \\
\hline Red blood cells with degenerated PMNs & 15 & 21.42 \\
\hline Lymphocytes & 43 & 61.42 \\
\hline Neutrophils & 1 & 1.42 \\
\hline Eosinophils & 2 & 2.85 \\
\hline Macrophages \& mesothelial cells & 6 & 8.57 \\
\hline Malignant cells & 11 & 15.71 \\
\hline
\end{tabular}




\section{ORIGINAL ARTICLE}

TABLE VII -PRIMARY MALIGNANCIES IN CASES OF BLOODY PLEURAL EFFUSION

\begin{tabular}{|l|l|l|}
\hline Malignancy & No. of cases & Percentage \\
\hline Lung & 10 & 38.46 \\
\hline Ovary & 3 & 11.53 \\
\hline Breast & 3 & 11.53 \\
\hline Oral & 1 & 3.84 \\
\hline Non-Hodgkin's & 1 & 3.84 \\
\hline Undiagnosed primary & 8 & 30.76 \\
\hline Total & $\mathbf{2 6}$ & $\mathbf{1 0 0}$ \\
\hline
\end{tabular}

